\section{(6) OPEN ACCESS}

\title{
Night work and prostate cancer risk: results from the EPICAP Study
}

\author{
Méyomo Gaelle Wendeu-Foyet, ${ }_{1}^{1}$ Virginie Bayon, ${ }^{2,3}$ Sylvie Cénée, ${ }_{1}$ Brigitte Trétarre, ${ }^{4}$ \\ Xavier Rébillard, ${ }^{5}$ Géraldine Cancel-Tassin, ${ }^{6}$ Olivier Cussenot, ${ }^{6,7,8}$ Pierre-Jean Lamy, ${ }^{5,9}$ \\ Brice Faraut, ${ }^{2,3}$ Soumaya Ben Khedher, ${ }^{1}$ Damien Léger, ${ }^{2,3}$ Florence Menegaux ${ }^{1}$
}

\begin{abstract}
${ }^{1}$ Team Cancer and Environment, Université Paris-Saclay, Université Paris-Sud, CESP (Center for Research in Epidemiology and Population Health), Inserm, Villejuif, France ${ }^{2}$ Centre du sommeil et de la vigilance, Hôtel Dieu, APHP, Paris, France

${ }^{3}$ Université Paris Descartes, Sorbonne paris Cité, EA 7330 VIFASOM, Sommeil-VigilanceFatigue et Santé Publique, Paris, France

${ }^{4}$ Hérault Cancer Registry, EA 2415, ICM, Montpellier, France ${ }^{5}$ Clinique Beau Soleil, Montpellier, France

${ }^{6} \mathrm{C}$ RePP, Hopital Tenon, Paris, France

Sorbonne Université, Institut Universitaire de Cancérologie, GRC $n^{\circ} 5$ ONCOTYPE-URO, Hopital Tenon, APHP, Paris, France

${ }^{8}$ Department of Urology, Assistance Publique- Hôpitaux de Paris, Hopital Tenon, Paris,

France

${ }^{9}$ Imagenome, Labosud, Montpellier, France
\end{abstract}

\section{Correspondence to}

Dr Florence Menegaux; florence.menegaux@inserm.fr

Received 9 January 2018 Revised 30 April 2018 Accepted 11 May 2018 Published Online First

19 June 2018
Check for updates

To cite: Wendeu-Foyet MG, Bayon V, Cénée $\mathrm{S}$, et al. Occup Environ Med 2018:75:573-581.

\section{ABSTRACT}

Objective To investigate the role of night work in prostate cancer based on data from the EPICAP Study. Methods EPICAP is a French population-based casecontrol study including 818 incident prostate cancer cases and 875 frequency-matched controls that have been interviewed face to face on several potential risk factors including lifetime occupational history. Detailed information on work schedules for each job (permanent or rotating night work, duration, total number of nights, length of the shift, number of consecutive nights) as well as sleep duration and chronotype, was gathered. Prostate cancer aggressiveness was assessed by Gleason Score. Results Night work was not associated with prostate cancer, whatever the aggressiveness of prostate cancer, while we observed an overall increased risk among men with an evening chronotype $(\mathrm{OR}=1.83,95 \% \mathrm{Cl} 1.05$ to 3.19). A long duration of at least 20 years of permanent night work was associated with aggressive prostate cancer $(\mathrm{OR}=1.76,95 \% \mathrm{Cl} 1.13$ to 2.75$)$, even more pronounced in combination with a shift length $>10$ hours or $\geq 6$ consecutive nights $(\mathrm{OR}=4.64,95 \% \mathrm{Cl} 1.78$ to 12.13; $\mathrm{OR}=2.43,95 \% \mathrm{Cl} 1.32$ to 4.47 , respectively). Conclusion Overall, ever night work, either permanent or rotating, was not associated to prostate cancer. Nevertheless, our results suggest that a long duration of permanent night work in combination with a long shift length or at least six consecutive nights may be associated with prostate cancer, particularly with aggressive prostate cancer. Further studies are needed to confirm those findings.

\section{INTRODUCTION}

Prostate cancer is the most common cancer in men in industrialised countries with more than 1000000 cases diagnosed worldwide in 2012, ${ }^{1}$ and more than 50000 cases of prostate cancer in France each year. ${ }^{2}$ Despite its high incidence, only age, ethnic origin and family history of prostate cancer are well-established risk factors, leaving aetiology of prostate cancer largely unexplained. Migrant studies have shown that Asian men living in USA have much higher prostate cancer incidence rates than their counterparts living in their native country suggesting the importance of westernised lifestyle and environmental factors in prostate cancer aetiology. ${ }^{3-5}$ Among those factors, a possible role of circadian disruption related to night work in prostate cancer risk has emerged, ${ }^{6} 7$ especially since the publication of the International Agency

\section{Key messages}

What is already known about this subject?

- A possible role of circadian disruption related to night work in prostate cancer risk was hypothesised based on the International Agency for Research on Cancer monograph that classified 'shift work leading to a disruption of circadian rhythm' as probably carcinogenic to humans.

- To date, 11 epidemiological studies have investigated night work in prostate cancer risk with conflicting results.

\section{What are the new findings?}

- Our results suggest that a long duration in combination with a long shift and/or at least six consecutive nights of permanent night work are associated with an increased risk of prostate cancer, and particularly aggressive prostate cancer.

- In addition, an overall increased risk of prostate cancer was also observed among night workers with an evening chronotype.

\section{How might this impact on policy or clinical} practice in the foreseeable future?

- The increasing prevalence of night shift work in the world population and the high incidence of prostate cancer make this research area a key issue for public and occupational health.

- Further studies are needed to enhance existing findings, and to identify night work patterns and individual characteristics that may have a strong impact on the internal circadian rhythm and therefore on cancer risk.

for Research on Cancer (IARC) monograph that classified in 2007 'shift work leading to a disruption of circadian rhythm' as probably carcinogenic to humans. ${ }^{8}$ This classification was based on sufficient evidence from experimental studies but limited evidence in humans, particularly for cancers other than breast cancer, including prostate cancer. Several biological mechanisms for how circadian disruption may be related to cancer have been hypothesised, among which: (A) exposure to light at night that suppresses the nocturnal peak of melatonin and its associated anticarcinogenic effects; (B) disruption of the circadian rhythm regulated by 
several clock genes controlling apoptosis and cell proliferation; (C) repeated phase shifting leading to internal desynchronisation and defects in the regulation of the circadian cell cycle; (D) sleep deprivation that alters immune function; and (E) lower vitamin $\mathrm{D}$ and harmful lifestyle factors. ${ }^{9-11}$

To date, 11 epidemiological studies, including 3 population-based case-control studies ${ }^{12-14}$ and 8 cohorts, ${ }^{15-22}$ have investigated the relationship between night work and prostate cancer with inconsistent results even though a recent meta-analysis concluded a $24 \%$ increased risk of prostate cancer in men exposed to night shift work, based on 8 of these studies. ${ }^{23}$ Several limitations in the epidemiological studies conducted so far may be pointed out: the different definitions of night work used (night work without any information, rotating shift, fixed and rotating night work) and few indicators studied (mostly duration). Moreover, very few studies took into account individual characteristics such as sleep patterns ${ }^{131618}$ or chronotype ${ }^{1317}$ as recommended by an IARC group of experts in $2011^{24}$ and only one study investigated night work according to prostate cancer aggressiveness. $^{13}$

In that context of a lack of evidence regarding night work and prostate cancer and given the large number of men involved in a non-standard day schedule $(\sim 20 \%),{ }^{25}{ }^{26}$ our objective was to investigate the role of night work, either permanent or rotating, in prostate cancer taking into account prostate cancer aggressiveness and individual characteristics, based on data from the EPICAP (Epidemiology of Prostate CAncer) Study.

\section{METHODS}

\section{Study population}

EPICAP is a population-based case-control study; details of its study protocol have been published elsewhere. ${ }^{27}$ Briefly, eligible cases were all men less than 75 years old newly diagnosed with histologically confirmed prostate cancer in 2012-2013 and residing in the Hérault region at the time of diagnosis. Controls were randomly selected from the general population and frequency-matched to the cases by 5 -year age groups. They were free of prostate cancer history and were residing in the same Hérault region as the cases. Quotas by socioeconomic status (SES) were established to yield a control group similar to the general population in terms of SES to control for potential selection bias arising from differential participation rates across SES categories. These quotas were calculated using the census data available in the Hérault region to ensure that the distribution by SES among controls was similar to the SES distribution in the general population of men in Herault of the same age.

In total, 819 incident cases of prostate cancer and 879 male population-based controls were enrolled in the study, which corresponds to a participation rate of $75 \%$ and $79 \%$, respectively.

All participants provided a written consent. The EPICAP Study was approved by the review board of the French institute of health and medical research (INSERM, n 01-040, November 2010) and authorised by the French data protection authority (CNIL n910485, April 2011).

\section{Data collection}

A face-to-face interview was conducted by trained clinical research nurses using a standardised computer-assisted questionnaire. During interview, we gathered information on sociodemographic characteristics such as educational level (highest diploma), personal and familial medical history, lifestyle factors including smoking status (never, former, current), physical activity (at least 1 hour per week during 1 year), alcohol drinking (at least once a month during 1 year), height and weight (measured during interview), sleep duration and individual chronotype.

Sleep duration was categorised into three groups according to the average number of sleep hours per night over the lifetime ( $<7$ hours, 7-8 hours and $>8$ hours per night).

The individual chronotype was assessed using the Morningness-Eveningness Questionnaire ${ }^{28}$ allowing us to classify cases and controls as a morning, evening or undifferentiated persons, according to the adapted classification from Taillard et al. ${ }^{29}$

Clinical information of prostate cancer cases were extracted from medical records including prostatic specific antigen (PSA) levels, Gleason Score and stage at diagnosis.

\section{Night work exposure assessment}

Cases and controls were asked to describe their entire work history for each job held for more than 6 months including general information on: beginning and ending dates, tasks involved, name and address of the company and if they had a non-day schedule for each given job. For each job for which a non-day schedule was indicated, they completed a specific 'night work' questionnaire gathering detailed information on their work time schedule. Night workers were defined as men who performed at least 270 hours of night work per year or three nights per month during at least 1 year, according to the French legal definition. ${ }^{30}$

Based on this definition, we categorised night work into permanent or rotating. We assigned men, who had performed both permanent and rotating night work during their entire work history, either to the permanent night work group when their duration of permanent night work was higher (24 cases, 19 controls) or to the rotating night work group when their duration of rotating night work was higher (7 cases, 19 controls). When the duration was equivalent for permanent and rotating night work (eight cases, five controls), men were assigned to both groups.

For each type of night work, overall, permanent or rotating, we were able to characterise several night work indicators: lifetime cumulative duration of night work $(<10$ years, 10-19 years, 20-29 years, $\geq 30$ years), number of consecutive nights ( $<6$ consecutive nights, $\geq 6$ consecutive nights), ${ }^{31}$ night shift length ( $<8$ hours, $8-10$ hours, $>10$ hours), ${ }^{32}$ and lifetime cumulative number of nights according to the median values among controls ( $\leq 1314$ nights, $>1314$ nights).

We also characterised night work as early morning shifts (shift starting between midnight and 06:00), late evening shifts (shift ending between 21:00 and 02:00) and overnight shifts (shift starting before 00:00 and ending after 05:00). Regarding rotating night work, we were also able to characterise the type of rotation (only forward, only backward, both) as well as the speed of rotation ( $\leq 3$ days, $4-5$ days, $\geq 6$ days).

\section{Statistical analysis}

All analyses were performed using the statistical analysis software SAS (V.9.4). Occupational questionnaires were missing for one case and four controls, restricting, therefore, our analyses to 818 cases and 875 controls. Associations between night work indicators and prostate cancer were assessed using unconditional logistic regression models systematically adjusted for age, ethnic origin and family history of prostate cancer. In addition, several potential confounding factors such as educational level, body mass index, physical activity and sleep duration were also taken into account in our models. We calculated all p-trend values using the original continuous variables. All analyses have 
been performed taking into account the aggressiveness of the tumour based on the Gleason Score at diagnosis (low aggressiveness: Gleason Score $<7$ or Gleason Score $=7$ including subjects for whom the two most commonly represented grades in the tumour are $3+4$, as well as those for which the two grades are not known, high aggressiveness: Gleason Score $>8$ or Gleason Score $=7$ including subjects for whom the two grades are $4+3$ ). Indeed, prostate cancer with a Gleason Score $=7(3+4)$ has been recognised to be less aggressive than prostate cancer with a Gleason Score $=7(4+3)$.

We also stratified analyses on individual characteristics such as sleep duration and chronotype.

\section{RESULTS}

Characteristics of the study population are reported in table 1. Age, ethnic origin, educational level, body mass index (BMI), physical activity, smoking status, alcohol consumption, chronotype and lifetime average sleep duration per night were identically distributed among cases and controls. As expected, a family history of prostate cancer in first-degree relatives was significantly higher in cases $(22.2 \%)$ than in controls $(8.8 \%)$ $(\mathrm{p}<0.0001)$.

Overall, 36\% of the cases and controls had ever worked at night $(\mathrm{OR}=0.97,95 \% \mathrm{CI} 0.79$ to 1.19$)$, of which $28 \%$ on permanent night work $(\mathrm{OR}=1.04,95 \% \mathrm{CI} 0.82$ to 1.32$)$ and $15 \%$ on rotating night work $(\mathrm{OR}=0.81,95 \% \mathrm{CI} 0.59$ to 1.16$)$ (table 2). The type of night shift (early morning, late evening and overnight shift), total duration of night work, total frequency of night work and number of consecutive nights, either on permanent or rotating night work, were not associated to prostate cancer. However, a shift length longer than 10 hours was associated with an elevated risk of prostate cancer $(\mathrm{OR}=1.57,95 \% \mathrm{CI} 1.01$ to $2.44)$, especially among permanent night workers $(\mathrm{OR}=1.88$, 95\% CI 1.08 to 3.26). Regarding rotating night work, neither the type of rotation nor the speed of rotation was associated with prostate cancer.

Table 3 shows associations between combined night work indicators and prostate cancer risk. A duration of night work of at least 20 years, in association with at least six consecutive nights or a shift length longer than 10 hours, slightly increased the risk of prostate cancer, even though not significantly $(\mathrm{OR}=1.45$, $95 \%$ CI 0.99 to 2.13 ; OR $=1.73,95 \%$ CI 0.95 to 3.16 , respectively). Those associations became significant for a duration of at least 30 years $(\mathrm{OR}=1.71,95 \% \mathrm{CI} 1.06$ to $2.76 ; \mathrm{OR}=2.49$, 95\% CI 1.11 to 5.61 , respectively) and were more specifically observed for permanent night work. A shift length longer than 10 hours in association with a cumulative number of at least 1314 nights or at least 6 consecutive nights also increased the risk of prostate cancer $(\mathrm{OR}=1.76,95 \% \mathrm{CI} 1.03$ to 3.03 ; $\mathrm{OR}=1.86$, $95 \%$ CI 1.05 to 3.27 , respectively), particularly for permanent night work $(\mathrm{OR}=2.36,95 \% \mathrm{CI} 1.21$ to 4.56 ; OR $=2.57,95 \% \mathrm{CI}$ 1.31 to 5.06 , respectively).

A duration of at least 20 years, at least six consecutive nights and a shift length of more than 10 hours of permanent night work were associated with aggressive prostate cancer $(\mathrm{OR}=1.76,95 \% \mathrm{CI} 1.13$ to $2.75 ; \mathrm{OR}=1.87,95 \% \mathrm{CI} 1.13$ to 3.11 ; $\mathrm{OR}=2.63$, 95\% CI 1.23 to 5.63 , respectively) (table 4). Those associations were more pronounced when night work indicators were combined two by two for permanent night work and aggressive prostate cancer with an OR of 2.43, 95\% CI 1.32 to 4.47 for a duration of at least 20 years and at least six consecutive nights, and an OR of $4.64,95 \%$ CI 1.78 to 12.1 for a duration of at least 20 years and a shift length longer than 10 hours.
Table 1 Sociodemographic characteristics of the EPICAP Study population

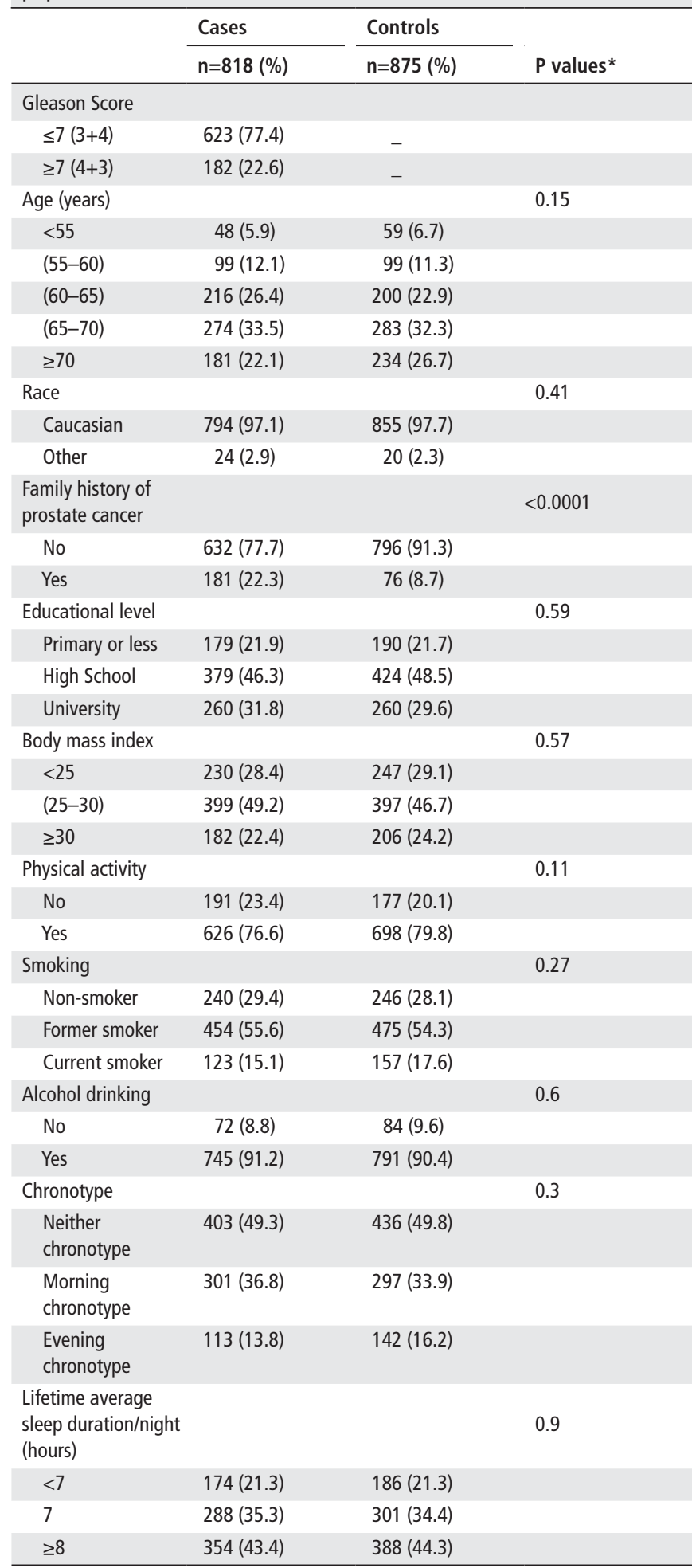

${ }^{*}$ Age-adjusted $p$ values (except for age).

No association was observed with rotating night work, either for aggressive or less aggressive prostate cancer.

Stratified analyses by chronotype (table 5) showed an elevated risk of prostate cancer among ever night workers with an evening chronotype $(\mathrm{OR}=1.83,95 \% \mathrm{CI} 1.05$ to 3.19$)$. The risk of prostate cancer also increased with the increase in duration of night work ( $\mathrm{p}$ trend $=0.01$ ) among men with an evening chronotype. 
Table 2 Associations between night work indicators and prostate cancer risk

\begin{tabular}{|c|c|c|c|c|c|c|}
\hline & \multicolumn{2}{|l|}{ Ever night work } & \multicolumn{2}{|c|}{ Permanent night work } & \multicolumn{2}{|c|}{ Rotating night work } \\
\hline & $\begin{array}{l}\text { Cases }(n=818) / \\
\text { controls }(n=875)\end{array}$ & $\mathrm{OR}^{*} \dagger$ & $\begin{array}{l}\text { Cases }(n=742) / \\
\text { controls }(n=769)\end{array}$ & $O R^{*} \dagger$ & $\begin{array}{l}\text { Cases }(n=616) / \\
\text { controls }(n=667)\end{array}$ & $\mathrm{OR}^{*} \dagger$ \\
\hline Never night work & $532 / 556$ & 1.0 (reference) & $532 / 556$ & 1.0 (reference) & $532 / 556$ & 1.0 (Rreference) \\
\hline Ever night work & $286 / 319$ & $0.97(0.79$ to 1.19$)$ & $210 / 213$ & 1.04 (0.82 to 1.32$)$ & $84 / 111$ & 0.81 (0.59 to 1.16$)$ \\
\hline Early morning shiftsł & $97 / 119$ & 0.87 (0.64 to 1.18$)$ & $61 / 76$ & 0.87 (0.60 to 1.25 ) & $36 / 43$ & 0.84 (0.52 to 1.35$)$ \\
\hline Late evening shifts§ & $119 / 131$ & $0.98(0.74$ to 1.30$)$ & $69 / 66$ & 1.10 (0.76 to 1.59$)$ & $50 / 66$ & 0.82 (0.55 to 1.23$)$ \\
\hline Overnight shifts & $161 / 190$ & $0.90(0.70$ to 1.16$)$ & $108 / 122$ & 0.92 (0.68 to 1.23$)$ & $58 / 70$ & 0.86 (0.59 to 1.26$)$ \\
\hline \multicolumn{7}{|c|}{ Total duration of night work (years) } \\
\hline$<20$ & $145 / 176$ & $0.90(0.70$ to 1.17$)$ & $102 / 107$ & 1.02 (0.75 to 1.38$)$ & $50 / 76$ & 0.72 (0.49 to 1.07 ) \\
\hline$<10$ & $87 / 113$ & 0.86 (0.63 to 1.18$)$ & $54 / 65$ & 0.91 (0.62 to 1.35$)$ & $39 / 53$ & 0.79 (0.50 to 1.22$)$ \\
\hline $10-19$ & $58 / 63$ & 0.98 (0.66 to 1.44$)$ & $48 / 42$ & 1.17 (0.76 to 1.83 ) & $11 / 23$ & $0.57(0.27$ to 1.21$)$ \\
\hline$\geq 20$ & $141 / 143$ & 1.05 (0.80 to 1.38$)$ & $108 / 106$ & 1.06 (0.78 to 1.44$)$ & $34 / 35$ & 0.99 (0.60 to 1.65$)$ \\
\hline $20-29$ & $50 / 58$ & 0.94 (0.63 to 1.42$)$ & $39 / 48$ & 0.87 (0.56 to 1.37$)$ & $19 / 14$ & 1.29 (0.62 to 2.68$)$ \\
\hline$\geq 30$ & $91 / 85$ & $1.12(0.80$ to 1.56$)$ & $69 / 58$ & 1.22 (0.83 to 1.79$)$ & $15 / 21$ & $0.78(0.39$ to 1.55$)$ \\
\hline$p$-trend & & 0.37 & & 0.26 & & 0.46 \\
\hline \multicolumn{7}{|c|}{ Total frequency of night work (number of cumulative nights) } \\
\hline$<1314$ & $132 / 159$ & 0.90 (0.69 to 1.18$)$ & $90 / 88$ & 1.05 (0.76 to 1.46$)$ & $54 / 82$ & 0.71 (0.49 to 1.04$)$ \\
\hline$\geq 1314$ & $154 / 160$ & 1.04 (0.80 to 1.35$)$ & $120 / 125$ & 1.03 (0.77 to 1.38$)$ & $30 / 29$ & 1.08 (0.63 to 1.87$)$ \\
\hline p-trend & & 0.94 & & 0.89 & & 0.92 \\
\hline \multicolumn{7}{|l|}{ Number of consecutive nights } \\
\hline$<6$ & $144 / 173$ & 0.90 (0.69 to 1.17$)$ & $95 / 98$ & 1.01 (0.74 to 1.39$)$ & $58 / 83$ & 0.77 (0.53 to 1.11$)$ \\
\hline$\geq 6$ & $124 / 108$ & 1.24 (0.93 to 1.67$)$ & $93 / 76$ & 1.33 (0.95 to 1.87$)$ & $26 / 27$ & 0.98 (0.55 to 1.74$)$ \\
\hline$p$-trend & & 0.25 & & 0.25 & & 0.83 \\
\hline \multicolumn{7}{|l|}{ Shift length (hours) } \\
\hline$<8$ & $18 / 46$ & $0.44(0.25$ to 0.78$)$ & $11 / 37$ & 0.32 (0.16 to 0.64 ) & $3 / 9$ & 0.42 (0.11 to 1.57 ) \\
\hline 8 to 10 & $97 / 131$ & 0.79 (0.59 to 1.07$)$ & $23 / 30$ & 0.86 (0.48 to 1.53 ) & $69 / 92$ & 0.79 (0.56 to 1.12$)$ \\
\hline$>10$ & $54 / 38$ & 1.57 (1.01 to 2.44$)$ & $38 / 22$ & 1.88 (1.08 to 3.26$)$ & $12 / 10$ & 1.29 (0.54 to 3.07$)$ \\
\hline$p$-trend & & 0.94 & & 0.29 & & 0.28 \\
\hline \multicolumn{7}{|l|}{ Direction of shift rotation } \\
\hline Forward & & & & & $55 / 71$ & $0.82(0.56$ to 1.21$)$ \\
\hline Backward & & & & & $11 / 13$ & 0.85 (0.37 to 1.98$)$ \\
\hline Forward and backward & & & & & $18 / 27$ & 0.74 (0.40 to 1.39$)$ \\
\hline \multicolumn{7}{|l|}{ Speed of shift rotation (days) } \\
\hline Short $(\leq 3)$ & & & & & $13 / 16$ & 0.80 (0.37 to 1.72$)$ \\
\hline Intermediate (4-5) & & & & $41 / 57$ & $0.82(0.53$ to 1.26$)$ & \\
\hline Long ( $\geq 6)$ & & & & & $20 / 20$ & 0.95 (0.49 to 1.83$)$ \\
\hline Short/intermediate/long & & & & & $14 / 21$ & 0.62 (0.28 to 1.37$)$ \\
\hline
\end{tabular}

${ }^{*}$ Adjusted for age, family history of prostate cancer, race, education level.

$+95 \% \mathrm{Cl}$.

\#Shifts starting before 05:00.

§Shifts ending between 21:00 and 02:00.

IShifts running from at least 00:00 to 05:00.

\section{DISCUSSION}

The EPICAP Study showed that a long duration of permanent night work in combination with a long shift length or at least six consecutive nights was associated with prostate cancer, particularly in men with aggressive prostate cancer. We also observed an overall increased risk among ever night workers in men with an evening chronotype.

Based on the existing epidemiological literature, the evidence of an association between night work and prostate cancer is still conflicting from one study to another. ${ }^{12-22}$ Overall, there seems to be a slight association between ever night work and prostate cancer, ${ }^{12} 141620$ although other studies did not find any association in men who had ever worked at night. ${ }^{13} 15$ 17-19 2122 The difference in assessment and definition of night work used across studies may explain some of the inconsistencies, and may represent different degrees of circadian disruption.
Overall, we did not find any association between night work indicators examined separately, either for permanent or rotating night work, and prostate cancer risk. However, we observed an increased risk of prostate cancer when night work indicators were jointly examined, particularly for a duration of at least 20 years of night work in combination with at least six consecutive nights or a shift length longer than 10 hours. Associations with a long duration of night work were observed in four studies with durations ranging from 10 years to 34 years, ${ }^{12-14} 16$ out of the five which reported the duration of night work. ${ }^{12-16}$ We observed a more pronounced association with a duration of at least 20 years for aggressive prostate cancer as also shown by the Spanish multicase-control study (MCC-Spain) (OR=1.63, 95\% CI 1.08 to 2.45$).{ }^{13}$ MCC-Spain was the only study to characterise intensity of night work and observed a slightly increased, but not significant, risk of prostate cancer in men who had worked at 
Table 3 Associations between combined night work indicators and prostate cancer risk

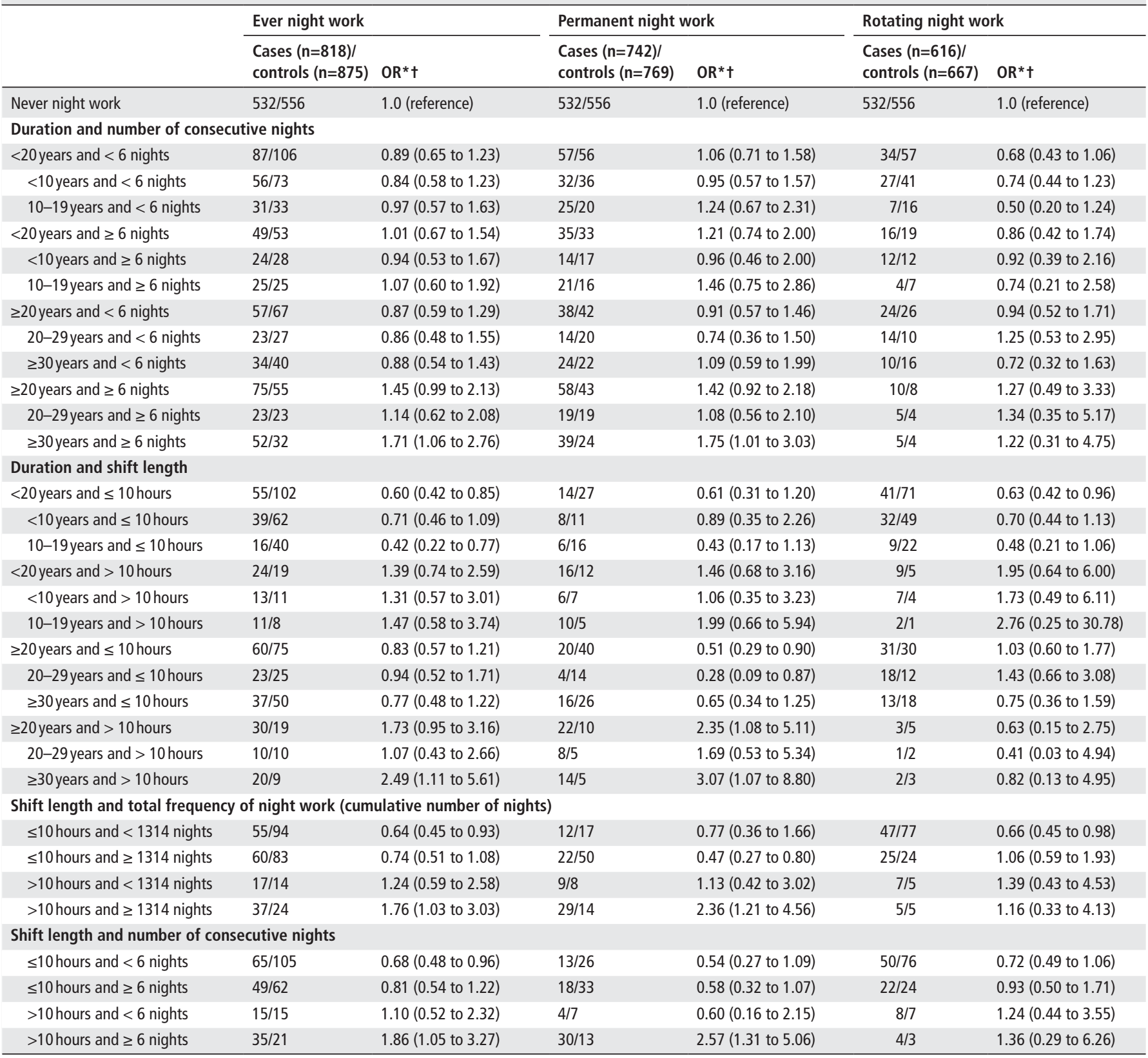

${ }^{*}$ Adjusted for age, family history of prostate cancer, race, education level.

$+95 \% \mathrm{Cl}$.

least 2857 nights over their lifetime $(\mathrm{OR}=1.30,95 \% \mathrm{CI} 0.97$ to 1.74$),{ }^{13}$ while our results did not show any association with the total number of nights worked except when total number of nights worked was combined with a shift length longer than 10 hours.

In our study, we were able to characterise night work with other indicators already studied in many breast cancer studies, as the number of cumulative nights and type (early morning, late evening and overnight) or length of the shift, but not yet studied in prostate cancer studies. Among those indicators, we observed an increased risk of aggressive prostate cancer in men working at least six consecutive nights and in men with a shift length longer than 10 hours, as already observed for breast cancer. ${ }^{31} 32$ Our results, more specifically observed in aggressive prostate cancer, may suggest that circadian disruption due to night work may play a role in cancer promotion, as observed in experimental animal studies. ${ }^{33}$

To date, our study is the first to include detailed information on rotating night work such as direction and speed of the rotation, as recommended by the IARC group of experts. ${ }^{24}$ We did not find any association with those rotating night work indicators.

Taking into account individual characteristics such as the individual chronotype, we found an association between ever night work and prostate cancer among men with an evening chronotype, as observed in two previous studies. ${ }^{13} 17$ This finding was surprising and did not support the hypothesis of a better adaptation or tolerance to night work in evening types. ${ }^{34}{ }^{35}$ Indeed, evening types usually got asleep more easily than morning types after night work and sleep more extensively. ${ }^{35}$ Therefore, chronotype may influence the individual sensitivity to circadian 
Table 4 Association of night work indicators and prostate cancer risk, by prostate cancer aggressiveness

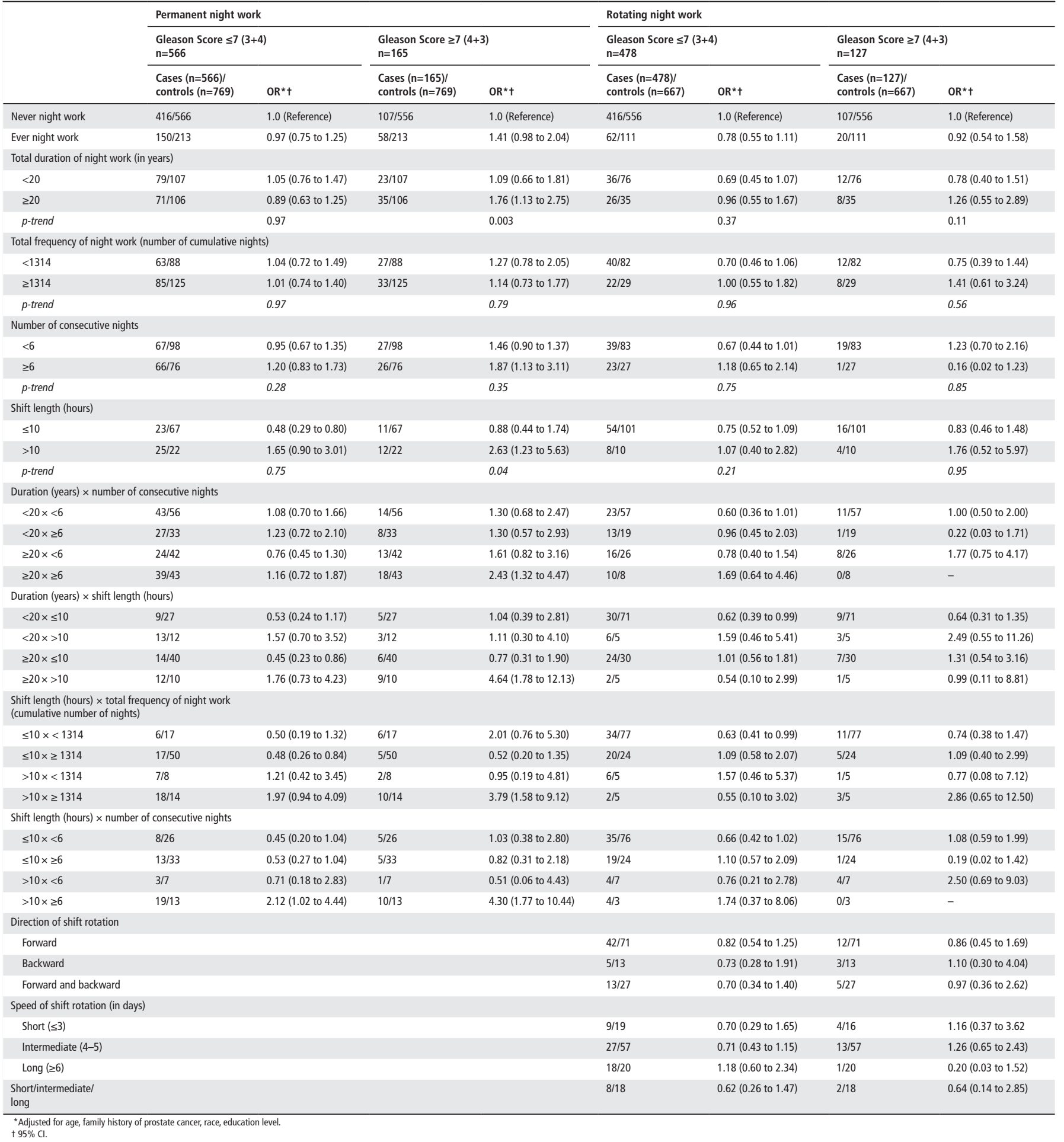

disruption due to night work and is one important component of circadian disruption to take into account in future studies.

To improve our understanding of the role of night work in prostate cancer risk, epidemiological studies need to better capture all aspects of circadian disruption. This includes identifying night work patterns and individual characteristics that may have a strong impact on the internal circadian rhythm and studying clock genes polymorphisms. Indeed, clock genes polymorphisms have been associated with chronotype, ${ }^{36}$ and they may also modify the association between night work and cancer. $^{37} 38$ Consideration of these polymorphisms in epidemiological studies on night work and cancer is therefore important.

Besides the circadian disruption driven by the biological clock, we also need to consider short sleep by itself, as a potential risk factor for cancer, especially on a long-term basis. ${ }^{939}$ Night work is associated daily with a sleep deficit of about 1 hour compared with day workers. It may be hypothesised, considering the role of slow wave sleep on immunity than sleep deficit by itself may promote cancer and increase its severity.

Our findings are based on a large carefully designed population-based case-control study conducted to specifically assess the 
Table 5 Association between night work indicators and prostate cancer risk, stratified by chronotype

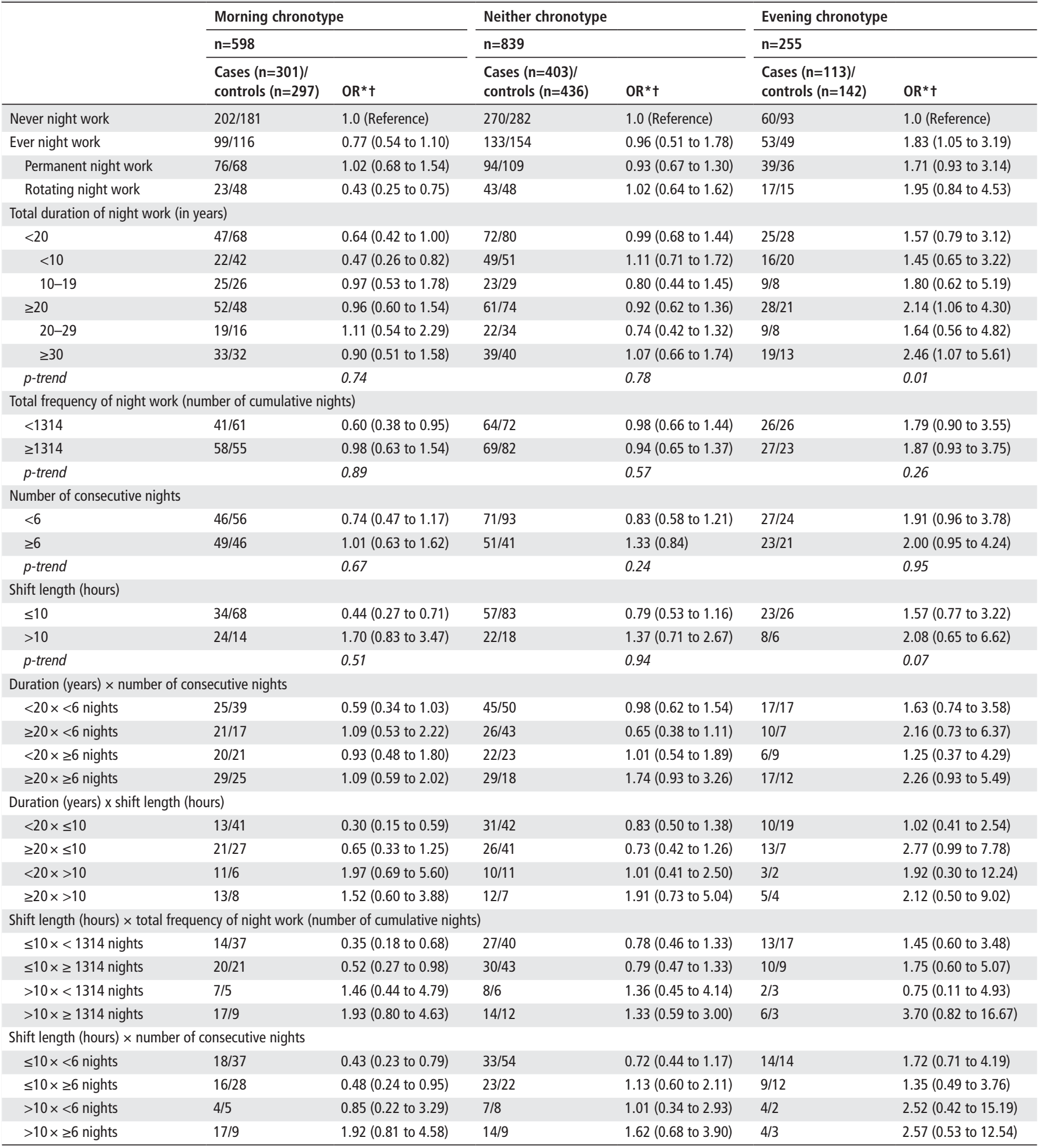

${ }^{*}$ Adjusted for age, family history of prostate cancer, race, education level.

+95\% Cl.

role of circadian disruption, including night work, in prostate cancer. The study has been implemented in the Hérault region of France, owing to the existence of a general Cancer Registry created since 1983, thus facilitating the exhaustive identification of all incident prostate cancer cases. In 2011, the Hérault Cancer Registry observed 770 new cases of prostate cancer, of which 575 were under 75 years of age. Considering that the number of cases observed in 2011 was identical, approximately
1150 new cases were expected during the study period (20122013). Overall, we identified 1098 eligible cases suggesting that the recruitment of cases in the EPICAP Study was exhaustive, thus limiting a potential selection bias. Controls were randomly selected from the general population of the Hérault region using quotas on age (5-year age groups) to reflect the age distribution of the cases. Moreover, quotas by SES have been established to yield a control group similar to the general population of the 
same age in the Hérault region, in terms of SES. After the selection process, we compared the distribution by SES between our control group and the male general population of the Hérault region and found no difference, indicating that no major selection bias by SES had occurred. In addition, the prevalence of night work in the EPICAP Study controls $(\sim 35 \%)$ is quite similar to that observed in the general population of men in France ${ }^{25}$ or in Europe. ${ }^{26}$ Despite the high overall prevalence of night work in our study, our results may have suffered from a lack of power in some subanalyses such as those stratified by chronotype or rotating night work according to prostate cancer aggressiveness.

Recall bias cannot be totally ruled out although it has been minimised by the use of standardised questionnaires and the similar interviewing conditions for cases and controls. Information on lifetime occupational history and on work time schedule has been self-reported by cases and controls which may have induced a classification bias. However, a recent study has compared working time information based on payroll data and questionnaires, highly validating self-reported assessment of shift work with night work and permanent night shifts, ${ }^{40}$ therefore strongly supporting our exposure assessment method.

All models were systematically adjusted for well-established risk factors of prostate cancer (age, ethnic origin and family history of prostate cancer in first-degree relatives) and our results remained unchanged after adjustment for potential confounders. Nevertheless, exposure to light at night during the sleep period of the cases and controls and night shift was not available in our data, therefore, we were not able to take into account those important variables for our analyses.

In conclusion, there was no overall association of ever night work, either permanent or rotating, to prostate cancer. Nevertheless, our results suggest that a long duration of permanent night work in combination with a long shift length or at least six consecutive nights may be associated with prostate cancer, particularly in men with aggressive prostate cancer. They also suggest that, overall, prostate cancer risk may be higher in men with an evening chronotype. Further studies, taking into account individual characteristics to circadian disruption such as individual chronotype, clock genes polymorphisms and prostate cancer aggressiveness, are needed to deeply understand role of circadian disruption related to night work in prostate cancer risk.

Acknowledgements The authors thank Pascal Guénel, director of the team Cancer and Environment, for our fruitful scientific discussions on the role of night shift work in cancers, especially his experience in breast cancer. The authors also thank the clinical research nurseswho were in charge of participants' interview, anthropometric measurements andbiological sample collection (Anne-Laure Astolfi, Coline Bernard, Oriane Boyer,Marie-Hélène De Campo, Sandrine Margaroli, Louise N'Diaye, SabinePerrier-Bonnet), and Christian Prad and Nadine Soller for help with patientmedical data collection within the Hérault Cancer Registry (Registre destumeursde I'Hérault, Montpellier, France). The authors also thank the EPICAPStudy group: Urologists: Didier Ayuso, Bruno Ségui, Vincent Abd El Fattah(Centre Hospitalier Bassin de Thau, Sète, France), Alain Guillaume, JeanPaulConstans, Olivier Delbos, Pierre Lanfray, Damien Rizet, Etienne Cuénant(Cabinet Urologie du Polygone, Montpellier, France), Michel Locci (Centre Hospitalier,Béziers, France), Etienne Cuénant (Clinique SteThérèse, Sète, France), NicolasDrianno, Bernard Marc, Paulo Soares (Polyclinique Saint Privat, Béziers, France), Antoine Faix, Samer Abdel Hamid, Bruno Ségui (Service Urologie, Clinique Beau Soleil, Montpellier, France), Samer Abdel Hamid (Clinique Saint Louis, Ganges, France), Thibaut Murez, Grégoire Poinas, Laurent Cabaniols, MaximeRobert, Rodolphe Thuret (Centre Hospitalo-Universitaire, Hôpital Lapeyronie,Montpellier, France); Pathologists: Didier Brel, Lysiane Schweizer, PhilippeNayraud, C. Lecam-Savin (Béziers), Roland Daniel, Jean Baptiste Perdigou, ChantalCompan, Mireille Granier, A Granier, Ruth Borges-Reis, A Badsi, Jean LouisBouzigues, Elisabeth Broquerie, Joëlle Simony, Frédéric Bibeau, Pierre Baldet, Isabelle Serre, Valérie Costes (Centre Hospitalo-Universitaire, HôpitalLapeyronie, Montpellier), Marie Laure Gaume (Sète); Biologists: F Montels(Service de Biologie Médicale, Institut du Cancer de Montpellier,
Montpellier, France)and Labosud laboratories: François et Pascal Dumas (Béziers, France), MartineBuono (Sète, France), Isabelle Bonnefille (Lodeve, France), Georges Ruiz(Lunel, France), Didier Paleirac (Clermont-l'Hérault, France).

Contributors FM, PJL, XR, BT: Study concept and design. OC, GCT, FM, PJL, XR, BT: Data acquisition. VB, BF, DL: Night work questionnaire design. MGWF, SBK, SC: Statistical analysis. MGW-F, VB, BF, DL, FM: Analysis and interpretation of data. MGWF, FM: Drafting of the manuscript.

Funding The EPICAP-Chrono project was funded by Institut National du Cancer, Fondation ARC and Ligue nationale contre le cancer. The EPICAP Study was funded by Ligue nationale contre le cancer Ligue contre le cancer du Val-de-Marne, Fondation de France, Agence nationale de sécurité sanitaire de l'alimentation, de l'environnement et du travail (ANSES). MGWF is funded by a 3-year doctoral allowance of the Doctoral School of Public Health (EDSP), Paris-Sud University, for her PhD.

Competing interests None declared.

Patient consent Obtained.

Ethics approval Institutional Review Board.

Provenance and peer review Not commissioned; externally peer reviewed.

Open access This is an open access article distributed in accordance with the Creative Commons Attribution Non Commercial (CC BY-NC 4.0) license, which permits others to distribute, remix, adapt, build upon this work non-commercially, and license their derivative works on different terms, provided the original work is properly cited and the use is non-commercial. See: http://creativecommons.org/ licenses/by-nc/4.0/

(C) Article author(s) (or their employer(s) unless otherwise stated in the text of the article) 2018. All rights reserved. No commercial use is permitted unless otherwise expressly granted.

\section{REFERENCES}

1 Globocan. Prostate cancer : estimated incidence, mortality and prevalence worldwide in 2012. 2012 http://globocan.iarc.fr/Pages/fact_sheets_cancer.aspx

2 Grosclaude P, Belot A, Daubisse Marliac L, et al. [Prostate cancer incidence and mortality trends in France from 1980 to 2011]. Prog Urol 2015;25:536-42.

3 Hsing AW, Devesa SS. Trends and patterns of prostate cancer: what do they suggest? Epidemiol Rev 2001:23:3-13.

4 Hsing AW, Sakoda LC, Chua SC. Obesity, metabolic syndrome, and prostate cancer. Am J Clin Nutr 2007;86:843S-57.

5 Lee J, Demissie K, Lu SE, et al. Cancer incidence among Korean-American immigrants in the United States and native Koreans in South Korea. Cancer Control 2007; 14:78-85.

6 Sigurdardottir LG, Valdimarsdottir UA, Fall K, et al. Circadian disruption, sleep loss, and prostate cancer risk: a systematic review of epidemiologic studies. Cancer Epidemiol Biomarkers Prev 2012;21:1002-11.

7 Wendeu-Foyet MG, Menegaux F. Circadian disruption and prostate cancer risk: an updated review of epidemiological evidences. Cancer Epidemiol Biomarkers Prev 2017;26.

8 Straif $K$, Baan R, Grosse Y, et al. Carcinogenicity of shift-work, painting, and firefighting. Lancet Oncol 2007;8:1065-6.

9 Costa G, Haus E, Stevens R. Shift work and cancer - considerations on rationale, mechanisms, and epidemiology. Scand J Work Environ Health 2010;36:163-79.

10 Fritschi L, Glass DC, Heyworth JS, et al. Hypotheses for mechanisms linking shiftwork and cancer. Med Hypotheses 2011;77:430-6.

11 Haus EL, Smolensky MH. Shift work and cancer risk: potential mechanistic roles of circadian disruption, light at night, and sleep deprivation. Sleep Med Rev 2013; 17:273-84

12 Conlon M, Lightfoot N, Kreiger N. Rotating shift work and risk of prostate cancer. Epidemiology 2007;18:182-3.

13 Papantoniou K, Castaño-Vinyals G, Espinosa A, et al. Night shift work, chronotype and prostate cancer risk in the MCC-Spain case-control study. Int J Cancer 2015; 137:1147-57.

14 Parent MÉ, El-Zein M, Rousseau MC, et al. Night work and the risk of cancer among men. Am J Epidemiol 2012;176:751-9.

15 Åkerstedt T, Narusyte J, Svedberg P, et al. Night work and prostate cancer in men: a Swedish prospective cohort study. BMJ Open 2017;7:e015751.

16 Behrens T, Rabstein S, Wichert K, et al. Shift work and the incidence of prostate cancer: a 10-year follow-up of a German population-based cohort study. Scand J Work Environ Health 2017:43:560-8

17 Dickerman BA, Markt SC, Koskenvuo M, et al. Sleep disruption, chronotype, shift work, and prostate cancer risk and mortality: a 30-year prospective cohort study of Finnish twins. Cancer Causes Control 2016;27:1361-70.

18 Gapstur SM, Diver WR, Stevens VL, et al. Work schedule, sleep duration, insomnia, and risk of fatal prostate cancer. Am J Prev Med 2014;46(Suppl 1):S26-33. 
19 Kubo T, Oyama I, Nakamura T, et al. Industry-based retrospective cohort study of the risk of prostate cancer among rotating-shift workers. Int J Urol 2011;18:206-11.

20 Kubo T, Ozasa K, Mikami K, et al. Prospective cohort study of the risk of prostate cancer among rotating-shift workers: findings from the Japan collaborative cohort study. Am J Epidemiol 2006;164:549-55.

21 Schwartzbaum J, Ahlbom A, Feychting M. Cohort study of cancer risk among male and female shift workers. Scand I Work Environ Health 2007;33:336-43.

22 Yong $\mathrm{M}$, Blettner $\mathrm{M}$, Emrich $\mathrm{K}$, et al. A retrospective cohort study of shift work and risk of incident cancer among German male chemical workers. Scand I Work Environ Health 2014;40:502-10.

23 Rao D, Yu H, Bai Y, et al. Does night-shift work increase the risk of prostate cancer? A systematic review and meta-analysis. Onco Targets Ther 2015;8:2817-26.

24 Stevens RG, Hansen J, Costa G, et al. Considerations of circadian impact for defining 'shift work' in cancer studies: IARC Working Group Report. Occup Environ Med 2011;68:154-62.

25 DARES. Le travail de nuit en 2012. Dares Analyses - Publication de la Direction de I'Animation de la Recherche, des Etudes et des Statistiques. 2014;62:1-8.

26 Parent-Thirion A, Fernandez Macias E, Hurley J, et al. Fourth European working conditions survey: european foundation for the improvement of living and working conditions. 2007:139.

27 Menegaux F, Anger A, Randrianasolo H, et al. Epidemiological study of prostate cancer (EPICAP): a population-based case-control study in France. BMC Cancer 2014;14:106.

28 Horne JA, Ostberg $\mathrm{O}$. A self-assessment questionnaire to determine morningnesseveningness in human circadian rhythms. Int J Chronobiol 1976;4:97-110.

29 Taillard J, Philip P, Chastang JF, et al. Validation of Horne and Ostberg morningnesseveningness questionnaire in a middle-aged population of French workers. J Biol Rhythms 2004;19:76-86.
30 RF-Md travail. Le travail de nuit. 2015 http://travail-emploi.gouv.fr/droit-du-travail/ temps-de-travail-et-conges/temps-de-travail/article/le-travail-de-nuit

31 Lie JA, Kjuus H, Zienolddiny S, et al. Night work and breast cancer risk among Norwegian nurses: assessment by different exposure metrics. Am J Epidemiol 2011;173:1272-9.

32 Cordina-Duverger E, Menegaux F, Popa A, et al. Night shift work and breast cancer: a pooled analysis of population-based case-control studies with complete work history. Eur J Epidemiol 2018;33:369-79.

33 Mao L, Dauchy RT, Blask DE, et al. Circadian gating of epithelial-to-mesenchymal transition in breast cancer cells via melatonin-regulation of GSK3ß. Mol Endocrinol 2012;26:1808-20.

34 Erren TC, Morfeld P. Shift work and cancer research: a thought experiment into a potential chronobiological fallacy of past and perspectives for future epidemiological studies. Neuro Endocrinol Lett 2013;34:282-6.

35 Saksvik IB, Bjorvatn B, Hetland $\mathrm{H}$, et al. Individual differences in tolerance to shift work-a systematic review. Sleep Med Rev 2011;15:221-35.

36 Hu Y, Shmygelska A, Tran D, et al. GWAS of 89,283 individuals identifies genetic variants associated with self-reporting of being a morning person. Nat Commun 2016;7:10448.

37 Grundy A, Schuetz JM, Lai AS, et al. Shift work, circadian gene variants and risk of breast cancer. Cancer Epidemiol 2013;37:606-12.

38 Truong T, Liquet B, Menegaux F, et al. Breast cancer risk, nightwork, and circadian clock gene polymorphisms. Endocr Relat Cancer 2014;21:629-38.

39 Gronfier C, Barthe B, Bérard D, et al. Évaluation des risques sanitaires liés au travail de nuit. Paris: ANSES, 2016:408.

40 Härmä M, Koskinen A, Ropponen A, et al. Validity of self-reported exposure to shift work. Occup Environ Med 2017;74:228-30. 